KLEINE TEXTE FUR VORLESUNGEN UND UBUNGEN HERAUSGEGEBEN VON HANS LIETZMANN

\title{
HISTORISCHE \\ ATTISCHE INSCHRIFTEN
}

AUSGEWÄHLT UND ERKLÄRT

voN

ERNST NACHMANSON

PRIVATIOO/EII IN LPPSALA

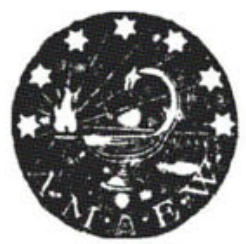

BONN

A. MARCUS UND E. WEBER'S VERLAG

I913 